\title{
STRATEGI MENINGKATKAN DAYA SAING EKONOMI PRODUK UMKM DAN WISATA BERBASIS DIGITAL BUSINESS DI DESA CIHIRUP, KECAMATAN CIAWIGEBANG, KABUPATEN KUNINGAN
}

\author{
${ }^{1)}$ Robi Awaluddin, ${ }^{2)}$ Yasir Maulana \\ Program Studi Manajemen, Universitas Kuningan \\ ${ }^{1)}$ Email : Awaluddin.robi@uniku.ac.id, \\ ${ }^{2)}$ Email : yasir@uniku.ac.id
}

\begin{abstract}
ABSTRAK
Cihirup adalah desa di kecamatan Ciawigebang, Kuningan, Jawa Barat, Indonesia, Cihirup merupakan Desa yang paling ujung dari Kecamatan Ciawigebang bagian utara yang menjadi pusat perbatasan antara Kabupaten Kuningan dan Kabupaten Cirebon. Masyarakatnya sendiri mayoritas petani, selain itu penggunaan bahasa dan tradisinya pun masih kental terhadap bahasa dan tradisi sunda. Setelah survey ke lapangan, Di desa cihirup memiliki produk siomay kering, kremes ubi, nugget ayam, tahu hingga rintisan objek pariwisata bangong. Namun, perlu diketahui bahwa banyaknya wirausaha di desa cihirup tidak serta-merta menambah penghasilan masyarakat. Kegiatan wirausaha dilaksanakan dengan sangat tradisional, akses pemasaran terbatas hanya di dalam desa dan dikerjakan dengan proses produksi sederhana. Maka atas latar belakang tersebut, kami menyimpulkan bahwa perlu diadakannya proses pendampingan, pelatihan dan pengembangan skala usaha yang dimiliki oleh penduduk cihirup sehingga pada akhirnya proses bisnis mereka akan berkembang yang berdampak pada peningkatan pendapatan masyarakat.
\end{abstract}

Kata Kunci : Daya Saing Ekonomi, Umkm, Digital Business 


\section{PENDAHULUAN}

Cihirup adalah desa di kecamatan Ciawigebang, Kuningan, Jawa Barat, Indonesia, Cihirup merupakan Desa yang paling ujung dari Kecamatan Ciawigebang bagian utara yang menjadi pusat perbatasan antara Kabupaten Kuningan dan Kabupaten Cirebon. Masyarakatnya sendiri mayoritas petani, selain itu penggunaan bahasa dan tradisinya pun masih kental terhadap bahasa dan tradisi sunda. Di desa cihirup mayoritas penduduk adalah wiraswasta, data lengkapnya adalah sebagia berikut:

\section{MATA PENCAHARIAN POKOK}

\begin{tabular}{|l|l|l|}
\hline Jenis Pekerjaan & Laki-laki & Perempuan \\
\hline Petani & 185 orang & 6 orang \\
\hline Buruh Tani & 216 orang & 15 orang \\
\hline Pegawai Negeri Sipil & 8 orang & 10 orang \\
\hline Pedagang barang kelontong & 96 orang & 9 orang \\
\hline Peternak & 1 orang & 0 orang \\
\hline Montir & 2 orang & 0 orang \\
\hline Dokter swasta & 3 orang & 0 orang \\
\hline Perawat swasta & 2 orang & 1 orang \\
\hline Bidan swasta & 0 orang & 2 orang \\
\hline TNI & 1 orang & 0 orang \\
\hline Guru swasta & 5 orang & 9 orang \\
\hline Pedagang Keliling & 40 orang & 9 orang \\
\hline Tukang Kayu & 42 orang & 0 orang \\
\hline Pembantu rumah tangga & 523 orang \\
\hline Karyawan Perusahaan Swasta & orang \\
\hline
\end{tabular}




\begin{tabular}{|c|c|c|}
\hline Karyawan Perusahaan Pemerintah & 5 orang & 0 orang \\
\hline Wiraswasta & 880 orang & 85 orang \\
\hline Konsultan Manajemen dan Teknis & 0 orang & 1 orang \\
\hline Tidak Mempunyai Pekerjaan Tetap & 153 orang & 78 orang \\
\hline Belum Bekerja & 482 orang & 458 orang \\
\hline Pelajar & 571 orang & 509 orang \\
\hline Ibu Rumah Tangga & orang & 876 orang \\
\hline Purnawirawan/Pensiunan & 3 orang & 4 orang \\
\hline Perangkat Desa & 6 orang & 1 orang \\
\hline Buruh Harian Lepas & 133 orang & 41 orang \\
\hline Pemilik perusahaan & 2 orang & 0 orang \\
\hline Pengusaha perdagangan hasil bumi & 4 orang & 0 orang \\
\hline Buruh usaha jasa transportasi dan perhubungan & 1 orang & 0 orang \\
\hline Pemilik usaha warung, rumah makan dan restoran & 1 orang & 1 orang \\
\hline Jasa pengobatan alternatif & 0 orang & 1 orang \\
\hline Sopir & 11 orang & 0 orang \\
\hline Tukang Jahit & 2 orang & 1 orang \\
\hline Tukang Kue & 0 orang & 1 orang \\
\hline Tukang Rias & 0 orang & 1 orang \\
\hline Karyawan Honorer & 2 orang & 3 orang \\
\hline Pialang & 1 orang & 0 orang \\
\hline Wartawan & 1 orang & 0 orang \\
\hline
\end{tabular}




\begin{tabular}{|l|l|l|}
\hline \hline Tukang Cukur & 1 orang & 0 orang \\
\hline Tukang Las & 3 orang & 0 orang \\
\hline Pemuka Agama & 1 orang & 0 orang \\
\hline Apoteker & 0 orang & 1 orang \\
\hline Bupati/walikota & 1 orang & 0 orang \\
\hline Jumlah Total Penduduk & 5.556 orang \\
\hline
\end{tabular}

Dari data di atas, diketahui bahwa mayoritas penduduk cihirup adalah wiraswasta, disusul buruh tani dan petani.Setelah survey ke lapangan, Di desa cihirup memiliki produk siomay kering, kremes ubi, nugget ayam, tahu hingga rintisan objek pariwisata bangong. Namun, perlu diketahui bahwa banyaknya wirausaha di desa cihirup tidak serta-merta menambah penghasilan masyarakat. Kegiatan wirausaha dilaksanakan dengan sangat tradisional, akses pemasaran terbatas hanya di dalam desa dan dikerjakan dengan proses produksi sederhana Maka atas latar belakang tersebut, kami menyimpulkan bahwa perlu diadakannya proses pendampingan, pelatihan dan pengembangan skala usaha yang dimiliki oleh penduduk cihirup sehingga pada akhirnya proses bisnis mereka akan berkembang yang berdampak pada peningkatan pendapatan masyarakat.

\section{METODE}

\section{Pemetaan}

Pemetaan potensi bisnis di desa cihirup dilakukan dengan survey langsung ke lapangan, menemui perangkat desa, pengurus Badan Usaha Milik Desa dan pemilik usaha local di desa cihirup yang dilakukan secara seksama.

\section{Analisis Potensi UMKM Desa Cihirup}

Setelah pemetaan dilakukan, maka tahap selanjutnya adalah melakukan analisis potensi Usaha yang terdapat di desa cihirup, analisis dilakukan dengan cara FGD (Focus Group Discussion) antara Perangkat Desa, Karang Taruna, Pemilik Usaha dan Penulis.

\section{Desain Kurikulum Pelatihan Bisnis}

Setelah melakukan analisis potensi UMKM di desa Cihirup maka langkah selanjutnya 
adalah mendesain kurikulum pelatihan dan workshop bisnis untuk pelaku usaha UMKM yang potensial sehingga pada akhirna usaha tersebut dapat naik kelas dan pendapatan masyarakatnyapun meningkat. Kurikulum pelatihan mencakup manajemen produksi dan operasional, manajemen keuangan untuk UMKM, Manajemen Marketing, Manajemen Sumber Daya Manusia, dan Manajemen Bisnis Digital.

\section{Pengaplikasian dan Pengelolaan Produk Unggul}

Melakukan praktek Bisnis UMKM sesuai kurikulum yang diberikan sehingga lahirlah produk unggulan desa cihirup yang dapat bersaing di regional, nasional hingga internasional.

\section{HASIL DAN PEMBAHASAN}

\section{Pemetaan dan Analisis Produk Unggulan Desa Cihirup}

Cihirup merupakan desa paling ujung di sebelah utara yang terletak di kecamatan ciawigebang kabupaten Kuningan Jawa Barat. Desa Cihirup berbatasan langsung dengan kabupaten Cirebon. Secara demografis, mayoritas penduduk desa cihirup memiliki profesi sebagai pelaku usaha mikro. Hasil dari pemetaan dan Focus Group Discussion antara penulis, perangkat desa, dan pelaku usaha di desa cihirup, disimpulkan bahwa produk yang akan dijadikan sebagai produk unggulan adalah siomai kering mini dan keremes ubi hasil produksi local desa cihirup.

\section{Kurikulum Pelatihan dan Worshop Bisnis UMKM di Desa Cihirup}

Setelah melakukan pemetaan dan analisis potensi bisnis di desa cihirup dan dihasilkannya dua produk unggulan hasil dari FGD antar stakeholder, yaitu produk siomay mini kering dan keremes ubi, maka kurikulum pelatihan bisnisnya adalah sebagai berikut:

1. Brand Management, memberikan pelatihan penciptaan brand yang inovatif sehingga produk dapat dikenal luas dengan mudah, produk dengan citra merek inovatif dan kreatif juga unik akan mudah dikenal oleh konsumen.

2. Manajemen Produksi, memberikan pelatihan manajemen produksi kepada para pelaku bisnis agar proses produksi lebih efisien, higienis dan terstruktur dengan baik.

3. Packaging Management, memberikan pelatihan dan pendampingan dalam pembuatan kemasan yang higienis, unik dan menarik serta aman untuk produk olahan pangan yang terdapat di cihirup 
4. Pembentukan kelompok binaan tertarget untuk penerus / keberlanjutan usaha yang dikelola oleh BUMDES dan Karangtaruna serta pemilik usaha dan buruh tani yang mau dibimbing

5. Pelatihan digital marketing dan digital bisnis dengan tujuan mempermudah pemasaran dan kegiatan bisnis

6. Pelatihan manajemen keuangan berbasis digital, agar para pelaku usaha dapat mengetahui untung rugi serta cash flow usaha dengan bantuan teknologi mobile app.

7. Pelatihan kepariwisataan untuk mengelola rintisan objek wisata bangong.

\section{Pengaplikasian dan Pengembangan Produk}

Setelah dilakukannya pelatihan /workshop kepada para pelaku usaha mikro di desa cihirup, maka hasil dari praktek nya adalah sebagai berikut:

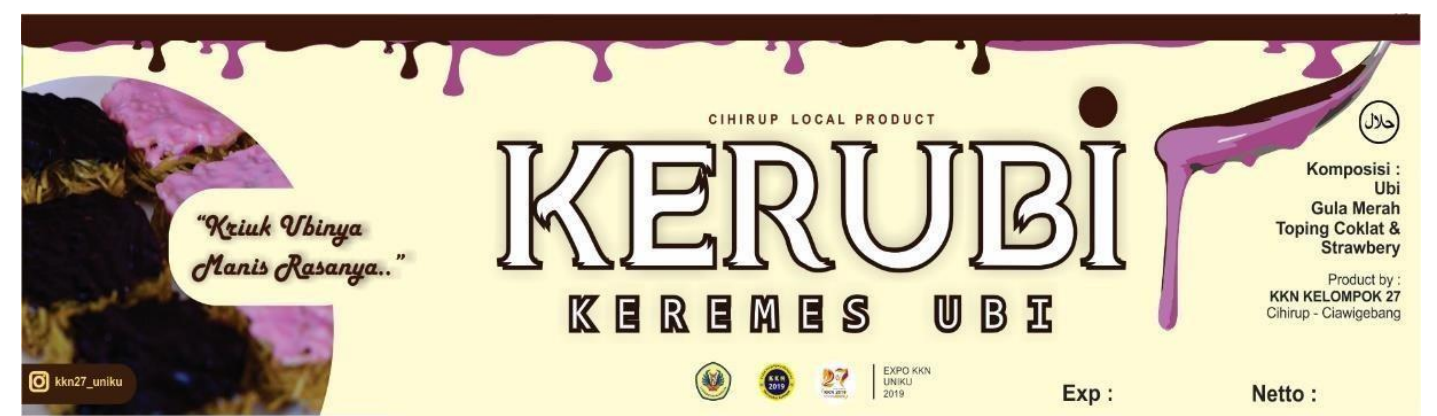

Gambar 1: Inovasi Kemasan Produk Keremes Ubi

\section{Inovasi Kerubi}

Inovasi Keremes Ubi menjadi Merek dagang KERUBI, dengan 3 varian toping yaitu Coklat, Stroberi dan Anggur. Keremes Ubi merupakan produk lokal desa cihirup yang sudah lama ada, eksistensinya sudah lebih dari sepuluh tahun, namun tidak adanya inovasi. Dengan adanya inovasi seperti pada gambar di atas yaitu inovasi pada kemasan produk jugan inovasi pada varian toping rasa berupa rasa coklat, stroberi dan anggur diharapkan dapat meningkatkan sales.

\section{Inovasi Siomi}

Sementara itu siomay kering mini juga merupakan produk lokal cihirup, namun dengan tidak adanya varian rasa dan kemasan yang sangat sederhana, penjualan siomai mini kering pun stagnan bahkan hamper bangkrut, maka dari itu setelah dianalisis maka siomay mini perlu memiliki merek yang menarik, kemasan yang unik dan varian rasa yang enak agar dapat meningkatkan penjualan, merek dari siomai kering mini kami inovasi menjadi SIOMI (Siomay 


\section{kering mini)}
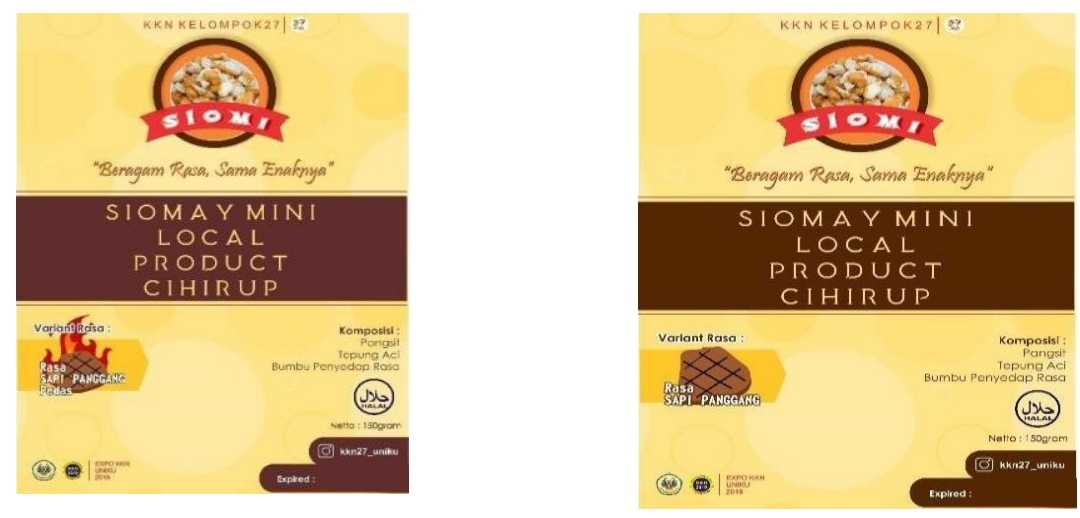

Gambar 2: Desain Kemasan Siomi Rasa Sapi Panggang Pedas

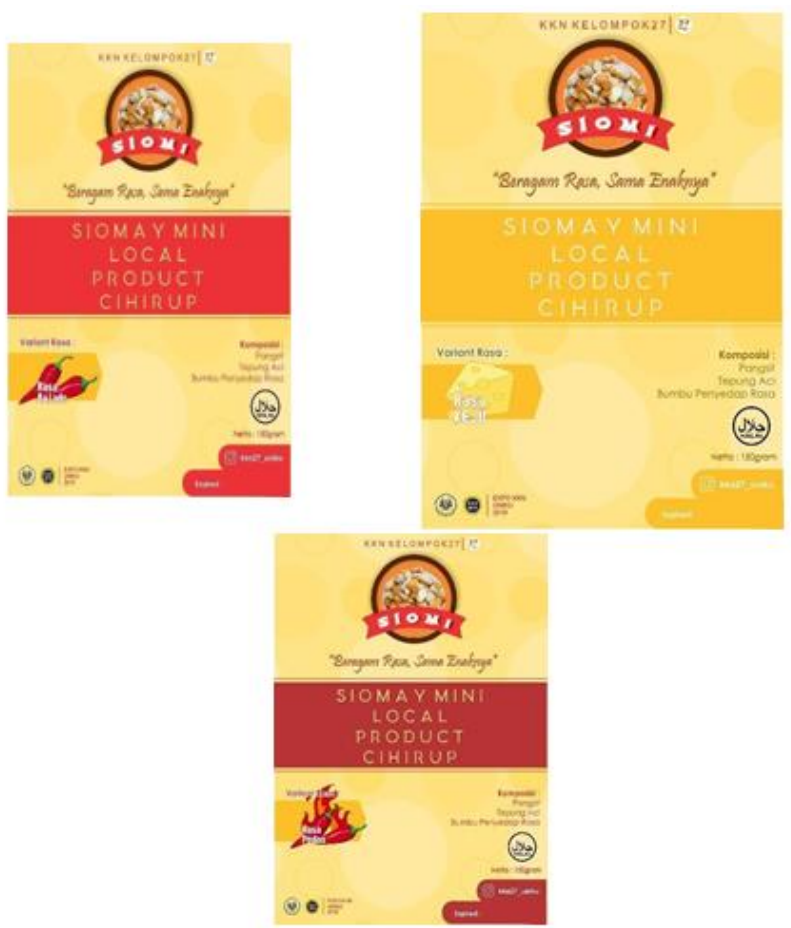

Gambar 3 aneka varian rasa Siomi dengan inovasi kemasan baru 


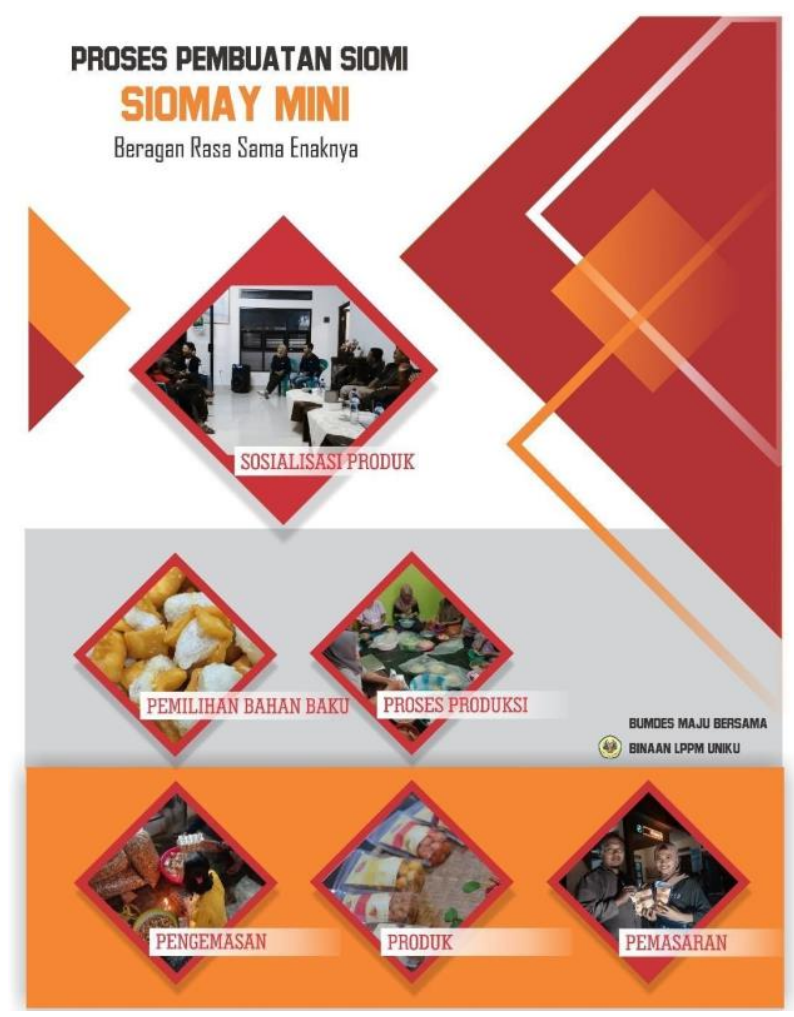

Gambar 4 Proses pembuatan Siomi dengan inovasi varian dan desain produk

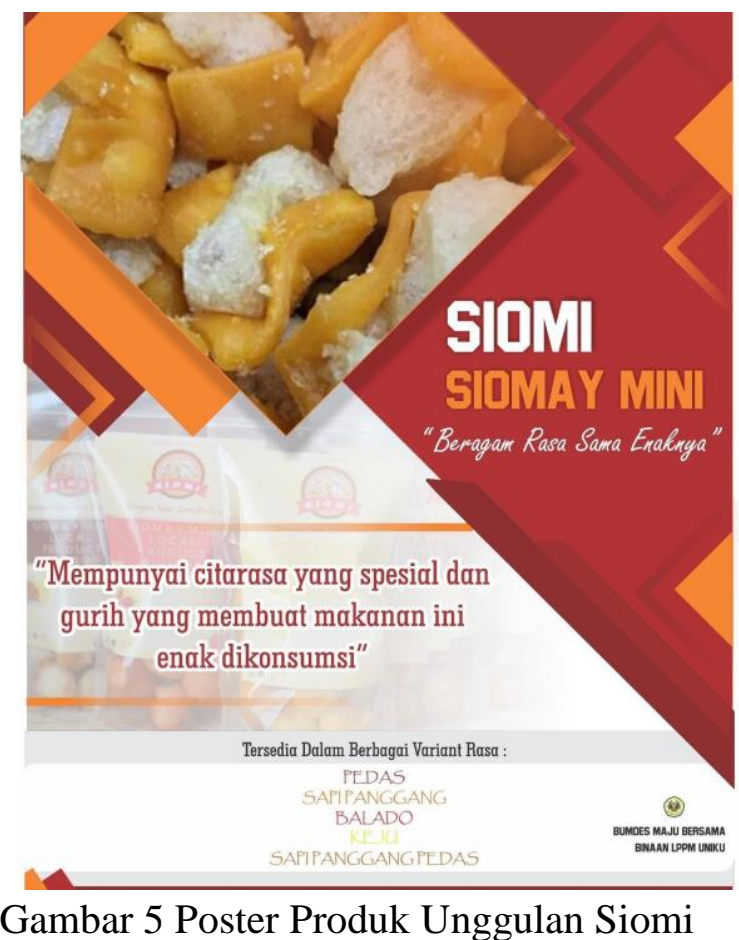




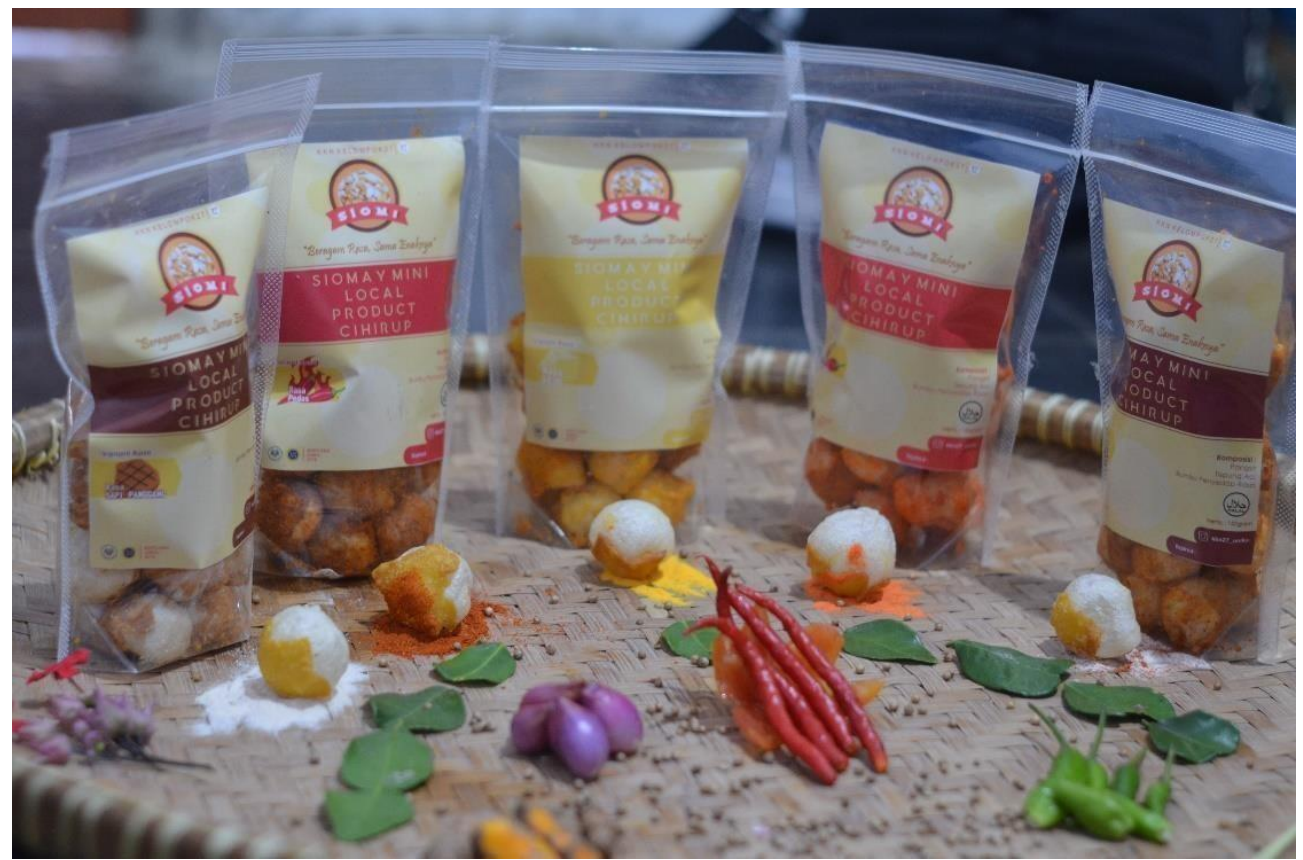

Gambar 6 Produk Unggulan Siomi

\section{Seminar Kewirausahaan}

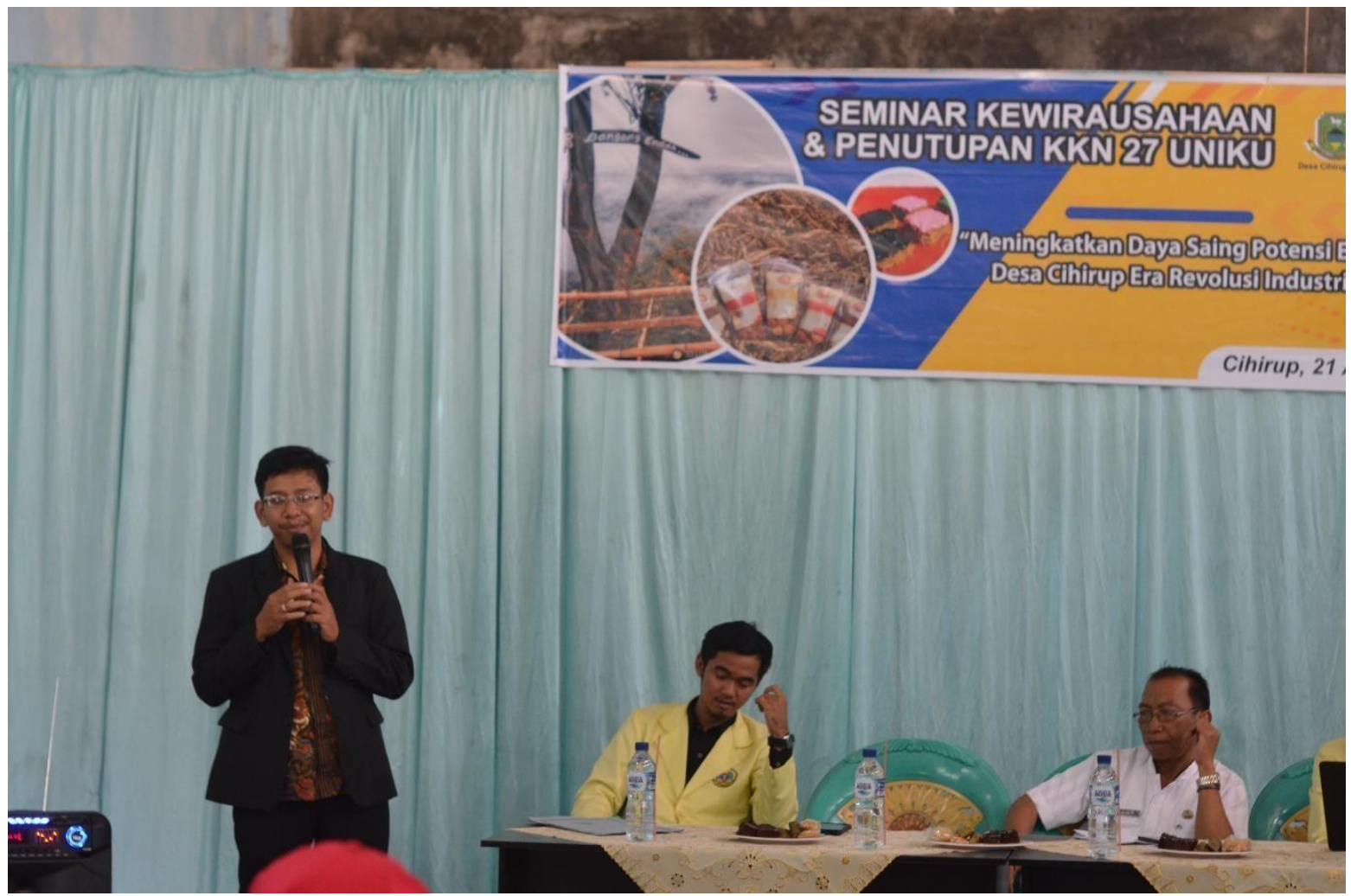

Gambar 7 Pelatihan dan workshop Kewirausahaan

Pada akhir pelatihan dan rangkaian kegiatan, diakukanlah seminar kewirausahaan 
dengan focus pada pengaplikasian digital bisnis dengan inovasi produk yang telah dilakukan. Saat ini digital bisnis dalam pemasaran, pengemasan dan produksi sangat penting dilakukan karna dapat menjangkap konsumen yang sangat luas, lebih efisien dan efektif terutama bagi pelaku usaha UMKM di desa sehingga dapat dengan cepat dan mudah memasarkan produknya (Hidayat, 2017).

\section{KESIMPULAN}

Hasil analisis dan pemetaan ditentukan dua produk asli desa cihirup yang akan diinovasi menjadi produk unggulan desa yaitu keremes ubi yang diinovasi menjadi Kerubi dan siomay mini yang diinovasi menjadi siomi. Produk unggulan tersebut diharapkan dapat bersaing dengan kualitas rasa dan kemasan yang unik. Sementara itu untuk pariwisata di desa cihirup masih dalam tahap pemetaan awal dikarenakan membutuhkan modal yang besar, sehingga pemetaannya pun harus dilakukan dalam kurun waktu jangka Panjang. Perlu dilakukan pengembangan lebih lanjut dan evaluasi pengembangan yang telah dilaksanakan. Pengembangan terutama harus dilakukan untuk bidang pariwisata karena saat ini masih tahap pembentukan awal, namun desa cihirup memiliki potensi pariwisata yang bagus yaitu bangong.

\section{DAFTAR PUSTAKA}

Alma, B. 2003. Manajemen Pemasaran dan Pemasaran Jasa.Edisi 2. Bandung: ALFABETA

Hidayat, A. (2017). Budaya Kerja, Kepuasan Kerja Dan Kinerja Pegawai Pt. Trijaya Medika Farma: Motivasi Sebagai Moderator. Sains: Jurnal Manajemen Dan Bisnis, 10(1), 377-389. https://doi.org/10.35448/jmb.v10i1.4274

Kotler, Philip. 2005. Prinsip-prinsip Pemasaran Jilid I. Jakarta: Erlangga

Kotler dan Keller. 2009. Manajemen Pemasaran. Jilid I. Edisi ke 13. Jakarta: Erlangga

Tjiptono, Fandy. 2008. Strategi Pemasaran, Edisi Ketiga. Andi, Yogyakarta 